\title{
Über eine angebliche Verbesserung der Blutmischpipette.
}

\author{
Von \\ Prof. Dr. K. Büixker in Tübingen.
}

Vor einiger Zeit hat W. Roerdansz ${ }^{1}$ ) in diesem Archiv Kritik an den Methoden der Blutverdünnung bei Vornahme von Blut. körperchenzählungen geübt und im Anschluss daran eine neue Blutmischpipette beschrieben. Da diese Kritik, besonders was meine Methorle der Blutkörperchenzählung betrifft, einige Ungenauigkeiten enthält, und eine Prüfung der neuen Mischpipette ergeben hat, dass bei ihr zwar einige Fehler der Thoma-Zeiss'schen Pipette vermieden, dafür aber neue eingeführt sind, welche das Instrument zur Blutverdünnung ungeeignet machen, so sehe ich mich veranlasst, darauf zu erwidern.

Die neueren Methoden der Blutkörperchenzählung ${ }^{2}$ ) machen sich frei von der zuerst von Potain angegebenen und dann besonders von $\mathrm{Thoma}$ und $\mathrm{Z}$ e iss übernommenen, mit einer ganzen Reihe von Fehlern behafteten Mischpipette und kehren zu getrennten Pipetten für die Abmessung des Blutes und der Verdünnungsflüssigkeit zurück.

Die Fehler der Mischpipette habe ich schon vor einiger Zeit eingehend besprochen ${ }^{8}$ ), so dass ich auf das dort Gesagte verweisen kann. Dass die Mischpipette auch andere Untersucher nicht

1) W. Roerdansz, Neue Blutmischpipette sowie Kritik über die Methode der Blutmischung behufs Vornahme der Blutkörperchenzählung. Dieses Archiv, Bd. 145, S. 261. 1912.

2) Über eine ausführliche Darstellung der Methoden der Blutkörperchenzählung siehe K. Bürker, Zählung and Differenzierung der körperlichen Elemente des Blutes. Tigerstedt's Handb. d. physiol. Methodik, Bd. 2, Abt. 5, S. 1. Verlag von S. Hirzel, Leipzig 1912.

3) K. Bürker, Über weitere Verbesserungen der Methode zur Zählung roter Blutkörperchen nebst einigen Zähiresultaten. Dieses Archiv, Bd. 142, 338. 1911. 
befriedigt hat, geht daraus hervor, dass eine gan ze Reibe von Neukonstruktionen ${ }^{1}$ ) vorliegt. Die ersten Verbesserungen hat F. Miescher an der Pipette anbringen lassen, ihm folgte R. May, der eine Pipette mit automatischer Einstellung angegeben hat. Eine etwas vereinfachte May'sche Pipette ist die Präzisionspipette von H. Hirschfeld. Eine gegen die Wärme der Hand geschützte und mit Hilfe einer Spritze zu füllende Mischpipette hat G. Galli konstruiert. Mit Präzisionssaugvorrichtungen haben J. Portmann, Koch und A. Pappenheim ihre Pipetten versehen lassen.

Getrennte Pipetten zur Abmessung des Blutes und der Verdünnungsflüssigkeit haben auch sehon G. Hay em ${ }^{2}$ ) und W.R Gowers ${ }^{3}$ ) benutzt; ihre Pipetten sind aber insofern fehlerhaft, als mit ihnen nur 2,5-5 cmm Blut und entsprechend geringe Mengen Verdünnungsflüssigkeit abgemessen werden; so kleine Blutmengen so exakt abzumessen, dass der Gesamtfehler der Abmessung 1\% nicht erreicht, wie man es verlangen muss, ist aber jedenfalls mit den von den genannten Autoren angegebenen Instrumenten nicht möglich. Um die Fehler der Abmessung auf ein Mindestmaass zu beschränkeń, habe ich der Blutpipette bis zur Marke eine Kapazität von $25 \mathrm{cmm}$ und eine Länge des kapillaren Raumes von etwa $90 \mathrm{~mm}$ erteilen, die Spitze der Pipette polieren und statt der Strichmarken Ringmarken anbringen lassen. Die Kapazität der Pipette für die Verdünnungsflüssigkeit beträgt $4975 \mathrm{cmm}$. Während ferner Hayem und Gowers kleine zylindrische, mit keiner besonderen Verschlussvorrichtung versehene Mischkölbchen benutzen, verwende ich zur Aufnahme von $5000 \mathrm{cmm}$ Blutmischung grössere Rundkölbchen mit möglichst engem Hals, in welchen ein Stopfen eingefügt wird; nie gelangt in diesen Kölbchen bei einiger Sorgfalt das verdünnte Blut aus dem kugeligen Teil in den zylindrischen oder gar an den Stopfen.

Gegen die Methode der Blutmischung vermittels Mischkölbchen und getrennter Pipetten wendet sich nun koer-

1) Siehe die S. ว๖2, Anm. 2 zitierte Arbeit des Verfassers S. 28 und 43.

2) G. Hayem, De la numération des globules du sang. Gazette hebdom. de médecine et de chirurgie (Paris), Bd. 12, S. 291. 1875, und Du sang et de ses altérations anatomiques, S. 27. Verlag von G. Mass on, Paris 1889.

3) W. R. Gowers, On the numeration of blood corpuscles. The lancet, Jahrg. 1877, Bd. 2, S. 797. 
d a nsz. Der Autor bemängelt zunächst, dass bei meiner Zählmethode ausser der Zählkammer noch vier Instrumente erforderlich sind; es sind sogar fünf, nämlich die Pipette zur Abmessung des Blutes, die Pipette zur Abmessung der Verdünnungsflüssigkeit, das Mischkölbchen und zwei einfache Übertragungspipetten zur getrennten Füllung der beiden Abteilungen des Zählraumes ${ }^{1}$ ). Die exakte Zăblung verlangt aber diese Instrumente; die in der Medizin vielfach üblichen Blitzdiagnosen, welche der Wissenschaft schon manchen Schaden zugefügt haben, sind mit den Instrumenten nicht beabsichtigt.

Dass die Reinigung dieser Instrumente nur wenig Zeit in Anspruch nimmt, ergibt sich aus folgendem. Die Pipette für die Abmessung der Verdünnungsflüssigkeit wird nur mit destilliertem Wasser ausgespült und dann aufrecht auf eine Unterlage von Filtrierpapier hingestellt, also innen nicht getrocknet. Die Reinigung und Trocknung der Blutpipette ist bei keiner Methode zu ungehen. Das Mischkölbchen wird nach dem Ausspülen durch destilliertes Wasser mit dem zylindrischen Teil nach abwärts auf Filtrierpapier gestellt, es trocknet dann über Nacht von selbst; hält man sich mehrere dieser leicht herzustellenden Mischkölbchen, so hat man immer ein trockenes. Die Übertragungspipetten werden nur an der Spitze gereinigt und getrocknet, was in der Zeit des Senkens der Blutkörperchen auf die Zählfäche ohne besonderen Zeitverlust geschieht.

Eine grosse Ungenauigkeit enthält nun die Schilderung des Verfahrens, das ich anwende, um das Blut aus der Blutpipette in die im Rundkölbchen befindliche Verdünnungsflüssigkeit zu übertragen; es sollen dabei unbekannte Mengen von Verdünnungsflüssigkeit in der Blutpipette zurückbleiben. Der Autor unterlässt zu erwähnen, dass ich in meiner Vorschrift verlange: "Ist die Mischung erfolgt, dann wird die Blutpipette in das verdünnte Blut eingetaucht und noch mehrere Male mit ihm ausgespült, möglichst ohne Luftblasen zu erzeugen $\left.{ }^{2}\right)$. Aber selbst wenn in der Blutpipette volle $25 \mathrm{cmm}$ Verdünnungsflüssigkeit zurückbleiben würden, also der ganze Inhalt bis zur Marke, so würde dadurch doch nur ein Fehler von $0,5 \%$ eingeführt werden.

Dass ferner die Abmessung der Verdünnungsflüssigkeit nur mit einem Fehler behaftet ist, der weit unter dem Fehler liegt, weleher

1) Siehe die S. 532, Anm. 3 zitierte Arbeit des Verfassers S. 339 u. f.

2) Dieses Archiv, Bd. 142, S. 347. 1911. 
einer Blutkörperchenzäblung anbaftet, gebt aus meiner Arbeit genugsam hervor, der Fehler erreicht nicht einmal 0,05\%, ein Fehler, den W. Ostwald und R. Luther ${ }^{1}$ ) für Pipetten von sogar nur 2 cem Inhalt angeben.

Von einer Unsicherheit, die in die Methode der Blutkörperchenzählung bei Anwendung getrennter Pipetten hineinkommt, kann also keine Redesein, die Methode wird dadurch vielmehr von der Unsicherheit derVerdünung, wiesiebeim Gebrauch der Blutmischpipette besteht, befreit.

Roerdansz rechnet dann ferner aus, dass die gesamten Operationen der Blutmischung bei meiner Methode 5-10 Minuten in Anspruch nehmen. Er macht nun folgenden Versuch. In einen kleinen offenen Porzellantiegel von $22,5 \mathrm{~mm}$ mittlerem innerem Durchmesser bringt er $5018 \mathrm{mg}$ destilliertes Wasser und findet dann, dass nach 10 Minuten $20-25 \mathrm{mg}$, also $0,4-0,5 \%$, verdunsten. Wem es um eine objektive Kritik zu tun ist, der wird den zu kritisierenden Versuch unter möglichst gleichen Umständen nachmachen. Der Autor hätte also statt eines offenen, $22,5 \mathrm{~mm}$ weiten Porzellantiegels ein verschliessbares Rundkölbchen mit nur $15 \mathrm{~mm}$ weitem Hals verwenden dürfen. Er hätte ferner das Kölbchen nur so lange offen lassen dürfen, als unbedingt nötig ist, also immer nur Bruchteile einer Minute, im ganzen etwa 1-2 Minuten. Unter diesen Umständen hätte der Autor gefunden, dass der Verlust durch Verdunstung so gering ist, dass er gar nicht in Betracht kommt. Bei einem Versuche, den ich angestellt habe, und bei dem die Zimmertemperatur $16,5^{\circ} \mathrm{C}$., der Luftdruck $734,5 \mathrm{~mm} \mathrm{Hg}$ (red.) und die relative Feuchtigkeit der Luft, mit dem D a n i ell' schen Hygrometer bestimmt, $40-50 \%$ betrug; nahmen 5,0615 g H a y e m 'scher Lösung im Rundkölbchen, während es im Wagekasten nicht nur 5-10, sondern sogar 30 Minuten offenstand, um $0,0015 \mathrm{~g}$ i. e. $0,03 \% \mathrm{ab}$, also um so wenig, dass von diesem Verlust abgesehen werden kann.

Schliesslich bemängelt der Autor, dass an den Pipetten in der Nähe der Marke keine Hilfsteilungen angebracht seien. Der Autor scheint nicht zu wissen, dass diese Hilfsteilungen sich nicht

1) W. Ostwald and R. Lu the r, Hand- und Hilfsbuch zur Ausführung physiko-chemischer Messungen, 2. Aufl, S. 132. Verlag von W. Engelmann, Leipzig 1902. 
bewährt haben, aus Gründen, welche offen zutage liegen; erstens wird der Meniskus nicht immer an einem Hilfsteilstrich liegen, dann ist man wieder auf unsichere Schätzungen angewiesen, und zweitens ist die Berechnung, welche bei den Zählmethoden auf Grund bestimmter Konstanten des Zählapparates auf eine einfache Formel gebracht ist, wieder mehr kompliziert. Auch bei Versuchen der Miescher' schen Schule ${ }^{1}$, welche zuerst solche Hilfsteilungen benutzt hat, haben sich diese als entbehrlich erwiesen.

Blickt man auf das Mitgeteilte zurück, so ergibt sich, dass die Roerdansz'sche Kritik sich in keinem einzigen Punkte als fruchtbar erwiesen und damit ihre Berechtigung verloren hat.

Nun zu der von dem Autor angegebenen und von der Firma E. Fleischhauer in Gehlberg (Thüringen) glastechnisch recht sorgfältig hergestellten neuen Mischpipette; eine Beschreibung und Abbildung der Pipette ist in der Roerdansz'schen Arbeit (S. 262) enthalten. Die wesentlichen Merkmale dieser Pipette sind folgende:

„1. Über der obersten Marke liegt ein besonderer Mischraum, der das oder die Mischkügelchen enthält, und auf einer Seite zu einer Standfläche abgefiacht ist.

2. An den Mischraum ist ein Ansaugrohr seitlich angebracht. Dieses Rohr mündet kapillar in den Mischraum und ist ebenso wie die Ansaugspitze der Pipette an seinem oberen Ende mit einer luftdicht aufgeschliffenen Glaskappe versehen.

3. Bei den Marken 0,5, 1,0 und 100 (resp. 10), welche in zylindrischen Kapillarröhren liegen, befinden sich, nach oben und unten hin verlaufend, Hilfsteilungen."

Bei dieser Pipette ist zunächst der Fehler der Thoma-Zeis sschen Pipette beseitigt, welcher dadurch bedingt ist, dass die das Ampullenvolumen begrenzenden Marken meist viel zu tief in den trichterförmigen Endstücken der Ampulle gelegen sind, wohin das Mischkügelchen nicht gelangen kann. Auch dass die Marken auf zylindrischen, gleich weiten Kapillarstücken angebracht sind, ist von

1) F. Egger, J. Karcher, F. Miescher, F. Suter und E. Veillon, Untersuchungen über den Einfluss des Höhenklimas auf die Beschaffenheit des Blutes. Naunyn's und Schmiedeberg's Arch. f. exper. Pathol. u. Pharmak., Bd. 89, S. 443.1897. 
Vorteil. Von Nachteil ist aber schon, dass die Marken keine völligen Ringmarken sind, und dass die Blutsäule, die bei 200 facher Verdünnung eingesaugt wird, nur $25 \mathrm{~mm}$ lang ist, so dass kleine Schätzungsfehler schon eine nicht zu vernachlässigende Rolle spielen. Dazu kommt, dass sich die Hilfsteilungen der Pipetten, wie erwähnt, nicht bewährt haben. Unverständlich ist, warum, wie die mir zur Verfügung stehende Pipette angibt, 101 fach statt 100 fach verdünnt wird; es fällt doch hier nicht, wie bei der Thoma-Zeiss'schen Pipette, die nach der Verdünnung in der Messkapillare befindliche reine Verdünnungsflüssigkeit beim Ausblasen der Blutmischung weg.

Zur Erhöhung der Dichte der Verdünnungsflüssigkeit empfiehlt ferner der Autor Zusatz von 1-5\% Sublimat zur Hayem'schen Lösung; nach meinen Versuchen lösen sich aber $5 \%$ Sublimat nur sehr langsam in der Lösung. In der Hayem'schen Lösung soll ferner Hämolyse eintreten; das habe ich aber trotz ausserordentlich vieler Versuche mit dieser Lösung nicht ein einziges Mal beobachtet. Nach alledem stehen die Roerdansz'schen Angaben auf unsicherem Boden.

Ganz ungeeignet ist schliesslich das Instrument zur Vornahme der Verdünnung des Blutes selbst, was freilich bei der Hintereinanderschaltung einer Messkapillare, einer Ampulle, einer weiteren Kapillare und eines zweiten Hohlraumes, des Mischraumes, zu erwarten ist, zumal, wenn das verdünnte und gemischte Blut dureh alle diese Räume hindurchgetrieben werden muss, um auf die Zählfläche zu gelangen.

Nach dem Autor saugt man z. B. das Blut bis zur Marke 0,5 ein und Verdünnungsflüssigkeit bis zur oberen Marke nach. Zur Mischung der eingesaugten Flüssigkeit soll man nun das Gerät nur um einen Winkel von $120^{\circ}$ neigen, um ein zusammenhängendes Abfliessen in den Mischraum zu bewirken. Bei der mir zur Verfügung stehenden Pipette findet aber ein Abfluss, selbst wenn die Pipette senkrecht gestellt wird, nicht statt; es bedarf eines Ansaugens, um die Blutmischung in das Mischgefäss zu befördern.

Beim Mischen von Blut und Verdünnungsflüssigkeit mit Hilfe des Mischkügelchens gelangt nun leicht das verdünnte Blut in das Ansatzrohr, welches den Schlauch trägt. Auch ist es mir niemals gelungen, durch vorsichtiges abwechselndes Neigen und Heben der Ansaugspitze die gemischte Flüssigkeit beliebige Male bis an die Spitze der Pipette vorzutreiben und wieder zurückfliessen zu lassen, 
538 K. Bürker: Über eine angebliche Verbesserung der Blutmischpipette.

vollends so, dass sich die Ampulle erst füllte, bevor die Mischung an die Messkapiliare gelangt. Die Ampulle mit den angrenzenden Kapillaren ist vielmehr nur dazu da, um die Blutmischuug mit Luftblasen zu durchsetzen und das ganze Verfahren der Mischung höchst unsicher zu gestalten.

Saugt man schliesslich alle Blutmischung in das Mischgefäss zurüek, so bleiben in den Kapillaren und in der Ampulle Blutkörperchen bängen, welche, wenn das Instrument einige Zeit stehen bleibt, festkleben und später schwer wieder in die Mischung eingehen.

Wie der Autor nach alledem von einer idealen ${ }^{1}$ ) Mischung des Blutes mit Hilfe dieses Instrumentes sprechen und die Fleischhauer'sche Pipette als das zurzeit vollkommenste Instrument zur Ausübung einer sicheren Abmessung, Mischung und Übertragung der erforderlichen Flüssigkeiten auf die Zählkammer und damit als wertvolles Hilfsmittel der Hämatologen bezeichnen kann, ist mir unverständlich. Es lohnt sich vielmehr gar nicht, in eine weitere genauere Untersuchung des Instrumentes durch Zählungen in dem mit ihm verdünnten Blute einzutreten.

Zusammenfassend ergibt sich, dass die Roerdanszsche Kritik der neueren Zählmethoden sich als unberechtigt und unfruchthar erwiesen hat, und dass die von ihm angegebene Mischpipettezurexakten Verdünnung des Blutes ungeeignet ist.

1) Das Wort „ideal" spielt in der Arbeit von Roerdansz bei Bewertung seiner Methode eine Rolle. Wer aber einige Erfahrung auf dem Gebiete der Blutkörperchenzählung besitzt, wird wissen, dass auch die beste Zählmethode von dem Ideal einer solchen noch einigermaassen entfernt ist. 